\title{
A Hybrid Space-Time Modelling Approach for Forecasting Monthly Temperature
}

RAVI RANJAN KUMAR ( $\square$ tan2ravi@gmail.com )

Visva-Bharati University: Visva-Bharati https://orcid.org/0000-0001-6174-3295

Kader Ali Sarkar

Digvijay Singh Dhakre

Institute of Agriculture

Debasis Bhattacharya

Institute of Agriculture

\section{Research Article}

Keywords: STARMA, ARCH/GARCH, temperature, nonlinearity, spatial weight matrix

Posted Date: January 11th, 2022

DOI: https://doi.org/10.21203/rs.3.rs-1088574/v1

License: (c) (i) This work is licensed under a Creative Commons Attribution 4.0 International License.

Read Full License 


\title{
A Hybrid Space-Time Modelling Approach for Forecasting Monthly Temperature
}

\author{
Ravi Ranjan Kumar ${ }^{\circledR}$, Kader Ali Sarkar ${ }^{1}$, Digvijay Singh Dhakre ${ }^{1}$, and Debasis Bhattacharya ${ }^{1}$ \\ $\triangle$ Ravi Ranjan Kumar tan2ravi@gmail.com (ORCID ID: 0000-0001-6174-3295) \\ ${ }^{1}$ Department of Agricultural Statistics, Institute of Agriculture, Visva-Bharati, Sriniketan, \\ West Bengal, India
}

\begin{abstract}
Spatio-temporal forecasting has various applications in climate, transportation, geo-statistics, sociology, economics and in many other fields of study. The modelling of temperature and it forecasting is a challenging task due to spatial dependency of time series data and nonlinear in nature. To address these challenges, in this study we proposed hybrid Space-Time Autoregressive Moving Average-Generalized Autoregressive Conditional Heteroscadicity (STARMA-GARCH) model in order to describe and identify the behaviour of monthly maximum temperature and temperature range in Bihar. At the modelling process of STARMA, spatial characteristics are incorporated into the model using a weight matrix based on great circle distance between the regions. The residuals from the fitted STARMA model have been tested by Brock, Dechert, and Scheinkman (BDS) and Autoregressive Conditional Heteroscadicity-Lagrange Multiplier (ARCH-LM) test for the behaviour of nonlinearity and ARCH effect respectively. The test results revealed that presence of both nonlinearity and ARCH effect. Hence GARCH modelling is necessary. Therefore, the hybrid STARMA-GARCH model is used to capture the dynamics of monthly maximum temperature and temperature range. The results of the proposed hybrid STARMA $\left(1_{1}, 0,0\right)-\operatorname{GARCH}(0,1)$ model has better modelling efficiency and forecasting precision over STARMA $\left(1_{1}, 0,0\right)$ model.
\end{abstract}

Keywords: STARMA, ARCH/GARCH, temperature, nonlinearity, spatial weight matrix.

\section{Introduction}

Agricultural sectors are highly influenced by weather and climatic factors. It is sensitive to short-term changes in weather and long term variations in climate. Weather parameters variability in small regions, a few kilometres in size, and it is important in many hydrological, agricultural and energy contexts. Agricultural yields are directly and indirectly affected by changes in climatic factors such as, rainfall, temperature, moisture, solar radiation etc., and the severity of extreme events like, floods, droughts, wind storms etc. Due to the effect of global warming there is a significant increase in global greenhouse gases and as a result there is steady rise in temperature of the planet earth. Therefore, mitigating climate change is one of the biggest challenges before humankind.

Temperature is the most important environmental factors at the earth surface. Forecasting of air temperature has been a crucial environmental factor required in many different areas such as agriculture, industry, energy, environment, tourism, etc. Therefore, there is a need of systematic and scientific prediction of temperature for better planning, policy making, and disaster management in the developing countries like India. There are various statistical methods used in forecasting monthly temperature. One of the most popular statistical methods used for forecasting temperature time series is Box-Jenkins' Autoregressive Integrated Moving Average (ARIMA). This model is suitable for only univariate and linear time series data. If the time series data set has nonlinear and spatio-temporal relationship, then ARIMA model is not suitable. 
The extension of univariate ARIMA time series models into the spatio-temporal domain results in a general class of Space-Time Autoregressive Integrated Moving Average (STARIMA) models (Cliff and Ord, I975a; Cliff et al. (1975)). It is used for the computation of linear dependencies between the variables in both time and space.

Application of spatial statistics mainly found in geo-statistics but in recent years the application of spatial statistics has been extended to sociology, economics, and environmental, ecological and agricultural sciences. Mention may be mode of some recent works which show interest in spatio-temporal models, using both spatial and temporal information, for example; Kamarianakis and Prastacos (2005) work on traffic flow data set, Kurta and Tunay (2015) developed STARMA model using of regional bank deposits data set, Zhao et al. (2018) Modelling on wind power data set, Rathod et al. (2018) modelling and forecasting on temperature data set, and Saha et al. (2020) developed forecasting model on rainfall data set. STARMA models are special cases of Vector Autoregressive Moving Average (VARMA) models but VARMA models involve more number of parameters compared to STARMA models (Brynjarsdottir and Berliner 2014), and Gupta and Robinson 2015)). However, one main disadvantage of using STARMA model is that it cannot deal with nonlinear data series. To analyse data sets with nonlinearity there are many statistical techniques such as ARCH technique first use by Engle (1982), GARCH technique (Bolerslev 1986), Threshold Autoregressive (TAR) technique (Tong and Lim 1980) etc.

In this paper an attempt has been made to develop a hybrid STARMA-GARCH model in order to investigate and predict spatio-temporal behaviour of monthly maximum temperature and temperature range. There are various hybrid statistical techniques available in the literature for modelling the rainfall data (Yusof et al. (2013)), forecasting the exchange rate data (Pahlavani and Roshan 2015), forecasting oil price data (Chaido Dritsaki 2018) but they all deal with only temporal data series. In real applications, weather data (rainfall, temperature, humidity etc.) constitute of dynamics involving spatial, temporal, linear and nonlinear features. Very few literatures have been found on spato-temporal time series data which deal with nonlinear phenomena. Hence, this paper has made an attempt to develop a hybrid STARMA-GARCH model that can capture the spatio-temporal behaviour with linear and nonlinear dynamics of the data series under consideration.

\section{Material and Methods}

\subsection{Study data}

The monthly maximum temperature and temperature range of Bihar have been used here. The state of Bihar is categorized into four comprehensive agro-climatic zones viz., Zone-I (North-West Alluvial Plains), ZoneII (North-East Alluvial Plains), and Zone-III (South Alluvial Plains). Further, Zone-III is divided into two parts Zone-III-A and Zone-III-B. For the present study, monthly maximum temperature and temperature range of eight districts of Zone-III-B, viz., Patna (PAT), Nalanda (NAL), Bhojpur (BHO), Rohtas (ROH), Gaya (GAY), Jahanabad (JAH), Aurangabad (AUR), and Kaimur (KAM) has been considered, which are presented in Fig. 1. The data set covers the period from January, 1981 to December, 2020. The data set on temperature has been collected from the NASA prediction of worldwide energy resources (https://power.larc.nasa.gov/data-accessviewer/). The data set from January, 1981 to December, 2019 and data set from January, 2020 to December, 2020 have been used for the purpose of model building and model validation respectively. 


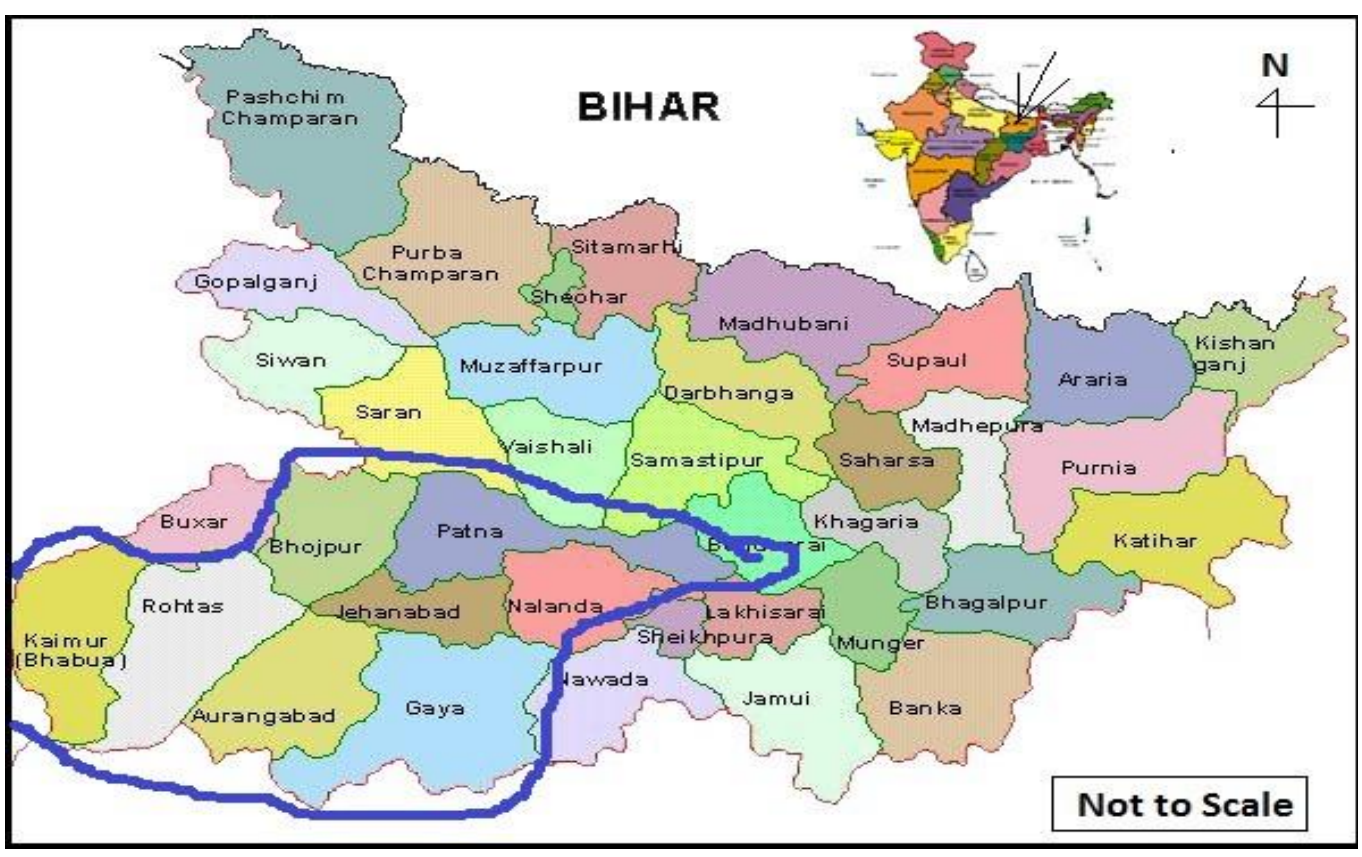

Fig. 1: Geographical map of Bihar

\subsection{STARMA Model}

It is to be noted that the space-time data series is a vector time series. The m-dimensional VARMA process of order $(p, q)$ is given by:

$$
\boldsymbol{Z}_{t}=\sum_{k=1}^{p} \phi_{k} \boldsymbol{Z}_{t-k}+\boldsymbol{\varepsilon}_{t}-\sum_{k=1}^{q} \theta_{k} \boldsymbol{\varepsilon}_{t-k}
$$

where $\boldsymbol{Z}_{t}$ is the $N \times 1$ vector of observations at time $t$ at $N$ locations and $\boldsymbol{\varepsilon}_{t}$ is the random error vector with $\boldsymbol{\varepsilon}_{t} \sim N(0$, $\left.\sigma^{2} \boldsymbol{I}_{N}\right)$ independently distributed at each time $t$, and $\sigma^{2} \boldsymbol{I}_{N}$ is an $N \times N$ positive definite variance matrix. Further, $\phi_{1}, \ldots, \phi_{p}$ are the autoregressive coefficients and $\theta_{1}, \ldots, \theta_{q}$ are the moving average coefficients at all $N \times N$ matrices with $\theta_{0} \equiv \boldsymbol{I}$. VARMA is not capable of modelling the spatial relationships and no assumptions of spatial stationarity can be made. Thus, incorporation of spatial dependence into a general VARMA model, turns VARMA model into STARMA model. A STARMA model is expressed as:

$$
\boldsymbol{Z}_{t}=\sum_{k=1}^{p} \sum_{l=0}^{\lambda_{\kappa}} \phi_{k l} \boldsymbol{W}^{l} \boldsymbol{Z}_{t-k}-\sum_{k=1}^{q} \sum_{l=0}^{m_{\kappa}} \theta_{k l} \boldsymbol{W}^{l} \boldsymbol{\varepsilon}_{t-k}+\boldsymbol{\varepsilon}_{t}
$$

where $\boldsymbol{Z}_{t}$ is the $N \times 1$ vector of observations at time $t$ at the $N$ locations. $p$ is the order of autoregressive, $q$ is the order of moving-average, $\lambda_{\kappa}$ is the spatial order of the $k^{\text {th }}$ autoregressive term, $m_{\kappa}$ is the spatial order of the $k^{\text {th }}$ moving-average term, $\phi_{k l}$ is the autoregressive parameter at temporal lag $k$ and spatial lag $l$ (scalar), $\theta_{k l}$ is the moving average parameter at temporal lag $k$ and spatial lag $l$ (scalar), $\boldsymbol{W}^{l}$ is the $N \times N$ spatial weight matrix with spatial order $l$ and $\varepsilon_{t}$ is the random disturbances are assumed to be normally distributed with

$$
\begin{gathered}
E\left[\boldsymbol{\varepsilon}_{t}\right]=0, \\
E\left[\boldsymbol{\varepsilon}_{t} \boldsymbol{\varepsilon}^{\prime}(t+s)\right]=\left\{\begin{array}{c}
\sigma^{2} \boldsymbol{I}_{N}, s=0 \\
0, s \neq 0
\end{array} \text { and } E\left[\boldsymbol{Z}_{t} \boldsymbol{\varepsilon}^{\prime}{ }_{t+s}\right]=0, \text { for } s>0\right.
\end{gathered}
$$

The STARMA $\left(p_{\lambda_{1}, \ldots \lambda_{p}}, q_{m_{1} \ldots m_{q}}\right)$ becomes a STAR model when $q=0$, which is expressed as:

$$
\boldsymbol{Z}_{t}=\sum_{k=1}^{p} \sum_{l=0}^{\lambda_{\kappa}} \phi_{k l} \boldsymbol{W}^{l} \boldsymbol{Z}_{t-k}+\boldsymbol{\varepsilon}_{t}
$$

when $p=0$, it becomes a STMA model, which is expressed as:

$$
\boldsymbol{Z}_{t}=\boldsymbol{\varepsilon}_{t}-\sum_{k=1}^{q} \sum_{l=0}^{m_{\kappa}} \theta_{k l} \boldsymbol{W}^{l} \boldsymbol{\varepsilon}_{t-k}
$$


The STARMA model-building procedure is similar to univariate ARIMA (Box and Jenkins 1976) model building procedure viz., identification of the model, estimation of the parameters, and diagnostic checking of the appropriateness of model for the observed data (Pfeifer and Deutsch 1980, 1980c, 1981, 1981a, b).

2.2.1. Preliminary Stage: Similar to ARIMA model, the first step is always to check for stationarity of time series data. If the time series data is nonstationary, then differencing should be done.

2.2.2. Identification: After making stationary of data series, next step is to examination of sample spacetime autocorrelation (ST-ACF) and space-time partial autocorrelation functions (ST-PACF) with incorporate the space weight matrices in the analysis. The theoretical space-time auto variances can be shown in Table 1.

Table 1: The ST-ACF and ST-PACF for STAR, STMA, and STARMA models.

\begin{tabular}{ccc}
\hline Model form & ST-ACF & ST-PACF \\
STAR $\left(\boldsymbol{p}_{\lambda_{1} \ldots \lambda_{p}}\right)$ & Tails off & Cuts off after $p$ time lags, \\
& & $\lambda_{p}$ spatial lags \\
STAR $\left(\boldsymbol{q}_{m_{1} \ldots \boldsymbol{m}_{\boldsymbol{q}}}\right)$ & Cuts off after $p$ time lags, $\lambda_{p}$ & Tails off \\
STARMA $\left(\boldsymbol{p}_{\lambda_{1} \ldots \lambda_{p}}, \boldsymbol{q}_{\boldsymbol{m}_{\mathbf{1}} \ldots \boldsymbol{m}_{\boldsymbol{q}}}\right)$ & spatial lags & \\
\end{tabular}

2.2.3. Estimation: After identification of proper STAR and STMA orders, next step is to estimate the parameters $\left(\phi_{k l}, \theta_{k l}\right)$ of the STARMA model. The parameters are estimated by Conditional maximum likelihood estimates (Pfeifer and Deutsch 1980b, c). To find the maximum likelihood estimators, the normality assumption of residuals should be satisfied i.e. $\boldsymbol{\varepsilon}_{t} \sim N\left(0, \sigma^{2} \boldsymbol{I}_{N}\right)$. Estimation of the parameters by maximum likelihood is a matter of minimizing the sum of squared residuals,

$$
S(\phi, \theta)=\sum_{t=1}^{T} \boldsymbol{\varepsilon}_{t}^{\prime} \boldsymbol{\varepsilon}_{t}
$$

where

$$
\boldsymbol{\varepsilon}_{t}=\boldsymbol{Z}_{t}-\sum_{k=1}^{p} \sum_{l=0}^{\lambda_{\kappa}} \phi_{k l} \boldsymbol{W}^{l} \boldsymbol{Z}_{t-k}+\sum_{k=1}^{q} \sum_{l=0}^{m_{\kappa}} \theta_{k l} \boldsymbol{W}^{l} \boldsymbol{\varepsilon}_{t-k},
$$

for $t=1,2, \ldots T$, while setting $\boldsymbol{\varepsilon}_{t}$ and $\boldsymbol{Z}_{t}$ equal to zero for $t<1$.

2.2.4. Diagnostic checking: The fitted model is verified by first checking if the residuals are white noise for the best fitted model, the residuals should be white noise, i.e., $\boldsymbol{\varepsilon}_{t} \sim N\left(0, \sigma^{2} \boldsymbol{I}_{N}\right)$. Auto correlation of residuals are tested by the Multivariate Box-Pierce test.

\subsection{Construction of Spatial Weight matrix:}

Prior to STARMA modelling, there is a need to define suitable spatial weight matrix $\left(\boldsymbol{W}^{l}\right)$. Choice of the spatial weight matrix is very important because different spatial weight matrices often lead to different results. There are different ways to construct spatial weight matrices, including shared border and distance between two locations. The simplest form of weights is the binary weight, where two areas shared a common boundary gets weight 1 and otherwise gets 0 (Griffith (1996) and (2009)). In a spatial weight matrix, row normalization is a 
common practice (each row total is 1) and weights reflects a hierarchical order of spatial neighbours. The first order neighbours are closer than the second order ones, and the second order neighbours are closer than the third order neighbours and so on. In addition to that, each space unit is defined as its zero spatial order neighbour, and the zero order spatial weight matrix $\left(\boldsymbol{W}^{0}\right)$ can be defined as unit matrix (Table 2). In this article, a spatial weight matrix $\left(\boldsymbol{W}^{1}\right)$ has been formed by taking weights that are inverse the distance between the two regions.

$$
w_{i j}=\left\{\begin{array}{c}
1 / d_{i j} \\
0
\end{array}\right.
$$

The elements are scaled such that

$$
\sum_{j=1}^{N} w_{i j}=1
$$

for each $i$. The distance $\left(d_{i j}\right)$ between the two geographical regions $i$ and $j$ is computed by using great circle distance formula of spherical law of cosines which is expressed as:

$$
d_{i j}=\operatorname{acos}\left(\sin \varphi_{1} \cdot \sin \varphi_{2}+\cos \varphi_{1} \cdot \cos \varphi_{2} \cdot \cos \nabla \lambda\right) \times R,
$$

where $\varphi_{1}=\operatorname{lat}_{1} \times \pi / 180, \varphi_{2}=\operatorname{lat}_{1} \times \pi / 180, \nabla \lambda=\left(\operatorname{lon}_{2}-\operatorname{lon}_{1}\right) \times \pi / 180$, and $R=$ radius of the earth $(6,371 \mathrm{~km})$.

For each location, Great circle distance $\left(d_{i j}\right)$ between the locations has been calculated using longitude and latitude coordinate (Table 3) which is represented in Table 4. Finally, The inverse distance weight matrix $\left(\boldsymbol{W}^{1}\right)$ has been created through row normalization processes as defined in Table $\mathbf{5}$.

Table 2: Spatial weight matrix of zero order $\left(\boldsymbol{W}^{0}\right)$

\begin{tabular}{ccccccccc}
\hline Location & AUR & BHO & GAY & JAH & NAL & KAM & PAT & ROH \\
\hline AUR & 1.000 & 0.000 & 0.000 & 0.000 & 0.000 & 0.000 & 0.000 & 0.000 \\
BHO & 0.000 & 1.000 & 0.000 & 0.000 & 0.000 & 0.000 & 0.000 & 0.000 \\
GAY & 0.000 & 0.000 & 1.000 & 0.000 & 0.000 & 0.000 & 0.000 & 0.000 \\
JAH & 0.000 & 0.000 & 0.000 & 1.000 & 0.000 & 0.000 & 0.000 & 0.000 \\
NAL & 0.000 & 0.000 & 0.000 & 0.000 & 1.000 & 0.000 & 0.000 & 0.000 \\
KAM & 0.000 & 0.000 & 0.000 & 0.000 & 0.000 & 1.000 & 0.000 & 0.000 \\
PAT & 0.000 & 0.000 & 0.000 & 0.000 & 0.000 & 0.000 & 1.000 & 0.000 \\
ROH & 0.000 & 0.000 & 0.000 & 0.000 & 0.000 & 0.000 & 0.000 & 1.000 \\
\hline
\end{tabular}

Table 3: Latitude and Longitude for all locations

\begin{tabular}{ccc}
\hline Location & Latitude & Longitude \\
\hline Aurangabad & $25.03651 \mathrm{~N}$ & $84.40261 \mathrm{E}$ \\
Bhojpur & $25.47361 \mathrm{~N}$ & $84.53691 \mathrm{E}$ \\
Gaya & $24.78501 \mathrm{~N}$ & $84.99271 \mathrm{E}$ \\
Jahanabad & $25.18341 \mathrm{~N}$ & $85.10731 \mathrm{E}$ \\
Nalanda & $25.20261 \mathrm{~N}$ & $85.54631 \mathrm{E}$ \\
Kaimur & $25.04031 \mathrm{~N}$ & $83.60651 \mathrm{E}$ \\
Patna & $25.60131 \mathrm{~N}$ & $85.13751 \mathrm{E}$ \\
Rohtas & $24.69371 \mathrm{~N}$ & $84.00201 \mathrm{E}$ \\
\hline
\end{tabular}


Table 4: Great circle distance for each locations

\begin{tabular}{ccccccccc}
\hline Location & AUR & BHO & GAY & JAH & NAL & KAM & PAT & ROH \\
\hline AUR & 0.00 & 50.44 & 65.75 & 72.81 & 116.62 & 80.20 & 96.96 & 55.55 \\
BHO & 50.44 & 0.00 & 89.26 & 65.79 & 105.82 & 105.24 & 61.91 & 102.09 \\
GAY & 65.75 & 89.26 & 0.00 & 45.78 & 72.59 & 142.65 & 91.93 & 100.56 \\
JAH & 72.81 & 65.79 & 45.78 & 0.00 & 44.22 & 151.94 & 46.57 & 124.03 \\
NAL & 116.62 & 105.82 & 72.59 & 44.22 & 0.00 & 196.12 & 60.43 & 165.66 \\
KAM & 80.20 & 105.24 & 142.65 & 151.94 & 196.12 & 0.00 & 166.05 & 55.47 \\
PAT & 96.96 & 61.91 & 91.93 & 46.57 & 60.43 & 166.05 & 0.00 & 152.47 \\
ROH & 55.55 & 102.09 & 100.56 & 124.03 & 165.66 & 55.47 & 152.47 & 0.00 \\
\hline
\end{tabular}

Table 5: Row normalized inverse distance spatial weight matrix $\left(\boldsymbol{W}^{1}\right)$

\begin{tabular}{ccccccccc}
\hline Location & AUR & BHO & GAY & JAH & NAL & KAM & PAT & ROH \\
\hline AUR & 0.000 & 0.203 & 0.155 & 0.140 & 0.087 & 0.127 & 0.105 & 0.184 \\
BHO & 0.218 & 0.000 & 0.123 & 0.167 & 0.103 & 0.104 & 0.177 & 0.108 \\
GAY & 0.169 & 0.125 & 0.000 & 0.244 & 0.153 & 0.078 & 0.121 & 0.110 \\
JAH & 0.125 & 0.139 & 0.200 & 0.000 & 0.206 & 0.060 & 0.197 & 0.074 \\
NAL & 0.104 & 0.115 & 0.168 & 0.275 & 0.000 & 0.062 & 0.202 & 0.073 \\
KAM & 0.192 & 0.147 & 0.108 & 0.102 & 0.079 & 0.000 & 0.093 & 0.279 \\
PAT & 0.118 & 0.184 & 0.125 & 0.246 & 0.189 & 0.069 & 0.000 & 0.069 \\
ROH & 0.237 & 0.129 & 0.131 & 0.106 & 0.079 & 0.238 & 0.079 & 0.000 \\
\hline
\end{tabular}

\subsection{BDS Test:}

The BDS test is a nonparametric test for serial independence based on the correlation integral of the scalar series and proposed by Brock, Dechert, and Scheinkman (1996). In this paper, this test will be used to check the non-linear dynamics in residuals for the fitted STARMA model. The test hypotheses are as follow:

Null hypothesis $\left(H_{0}\right)$ : Residuals are independently and identically distributed and linear.

Alternative hypothesis $\left(H_{1}\right)$ : Residuals are not independent and identical and non-linear.

Test statistic:

$$
\begin{aligned}
& B_{e, \epsilon}=\sqrt{T} \frac{A_{e, \epsilon}-A_{1, \epsilon}}{s_{e, \epsilon}}, \\
& A_{e, \epsilon}=\frac{2}{T_{e}\left(T_{e}-1\right)} \sum \sum_{e \leq s<t \leq T} I\left(z_{t}^{e}, z_{s}^{e}, \in\right), \\
& A_{1, \epsilon}=P\left(\left|z_{t}-z_{s}\right|<\epsilon\right)^{e} ; T_{e}=T-e+1, \\
& I\left(z_{t}^{e}, z_{s}^{e}, \in\right)=\left\{\begin{array}{lr}
1, & \text { if }\left|z_{t-i}-z_{s-i}\right|<\epsilon, i=0,1,2, \ldots, e-1 \\
0, & \text { Otherwise }
\end{array}\right.
\end{aligned}
$$

where $e=$ embedding dimension, $z_{t}=$ residuals data of STARMA model at time $t, t=1,2, \ldots, T$ and $B_{e, \epsilon}=$ converges to the standard normal distribution under the null hypothesis Decision: If the value of $\left|B_{e, \epsilon}\right|>1.96$, then the null hypothesis will be rejected, otherwise accepted at 5 $\%$ level of significance. 


\subsection{ARCH-LM Test:}

GARCH modelling starts by identifying whether or not the space-time series data contains heteroscedasticity. The residuals obtained from the data are checked by using ARCH-LM test to know the ARCH effect (Engle 1982; Tsay 2005).

The steps for ARCH-LM test:

I. Define the linear regression,

$$
\varepsilon_{t}^{2}=a_{0}+a_{1} \varepsilon_{t-1}^{2}+\cdots+a_{q} \varepsilon_{t-q}^{2}+\varepsilon_{t}
$$

where $\varepsilon_{t}$ denotes the error term, $q$ is the pre specified positive integer.

II. The test statistic is:

$$
\mathrm{LM}=T R^{2}
$$

where

$$
R^{2}=\frac{\sum_{i=1}^{n}\left(\widehat{x_{l}}-\bar{x}\right)^{2}}{\sum_{i=1}^{n}\left(x_{i}-\bar{x}\right)^{2}}
$$

and $T$ is total number of observation. Here $R^{2}$ follows a $\chi^{2}(q)$ distribution.

III. The null and alternative hypotheses are

$$
\begin{aligned}
& H_{0}: a_{1}=a_{2}=\cdots=a_{q}=0 \\
& H_{1}: \text { all are not equal of zero }
\end{aligned}
$$

\subsection{GARCH Model:}

If there is ARCH effect, then the next step involves in identifying the appropriate orders for the GARCH $(p, q)$ model. The GARCH model is a generalized form of ARCH model. The $\operatorname{GARCH}(p, q)$ model in which conditional variance is modelled as

$$
\sigma_{t}^{2}=\alpha_{o}+\sum_{i=1}^{q} \alpha_{i} \varepsilon^{2}{ }_{t-i}+\sum_{j=1}^{p} \beta_{j} \sigma^{2}{ }_{t-j},
$$

where $\alpha_{o}>0, \alpha_{i}>0, \beta_{j} \geq 0$ and $\sum_{i=1}^{q} \alpha_{i} \varepsilon_{t-i}^{2}+\sum_{j=1}^{p} \beta_{j} \sigma_{t-j}^{2}<1$.

\subsection{Propose Hybrid STARMA-GARCH Model:}

There are two phases in the hybrid STARMA-GARCH modelling. In the first phase, a STARMA model is fitted on stationary and linear space-time data and in the second phase, residuals of the STARMA model are fed as an input to the GARCH model. This hybrid model, which combines STARMA and GARCH model containing non-linear residuals patterns is applied to forecast the air temperature data.

\subsection{Diagnostic Checking of the Hybrid STARMA-GARCH Model:}

The diagnostic tests of hybrid STARMA-GARCH models are based on residuals. Normality of the residuals is tested using Ljung and Box $Q$-statistics (Ljung and Box 1978) for the serial correlation test. Test hypotheses are given below:

$$
\begin{aligned}
& H_{0} \text { : no serial correlation in the residuals } \\
& H_{1} \text { : there is serial correlation }
\end{aligned}
$$

The $Q$-statistic is given as:

$$
Q=N(N+2) \sum_{j=1}^{L} \frac{\widehat{\rho_{J}^{2}}}{(N-j)},
$$

where $N$ is the sample size, $L$ is the autocorrelation lags, $\widehat{\rho_{J}^{2}}$ is the square of the estimated autocorrelation at lag $j$.

Decision: If the value of $\mathrm{Q}>1.96$, then the null hypothesis will be rejected at $5 \%$ level of significance. 


\subsection{Forecast Evaluation:}

Mean absolute percentage error (MAPE) have been used to evaluate the forecast efficiency for which the formula is given below:

$$
\operatorname{MAPE}=\frac{1}{n} \sum_{i-1}^{n}\left|\frac{z_{i}-\hat{z}_{i}}{z_{i}}\right| \times 100
$$

where $n=$ total numbers of predicted value, $z_{i}=$ actual value at time $t$, and $\hat{z}_{i}=$ corresponding predicted value.

\section{Results and Discussion}

\subsection{Preliminary Stage}

Before proceeding to use STARMA modelling, it is important to check the stationary of the time series data. The results of the Augmented Dickey -Fuller test showed that spatio-temporal data series of all locations satisfy stationarity. The time series plots of data set (Fig. 2 and 3) indicate the presence of seasonality which needs to be removed before analysis. Therefore, the original time series data are seasonally adjusted by seasonal differencing with period 12. Finally, seasonally adjusted data series of each location become stationary and have been used for analysis.
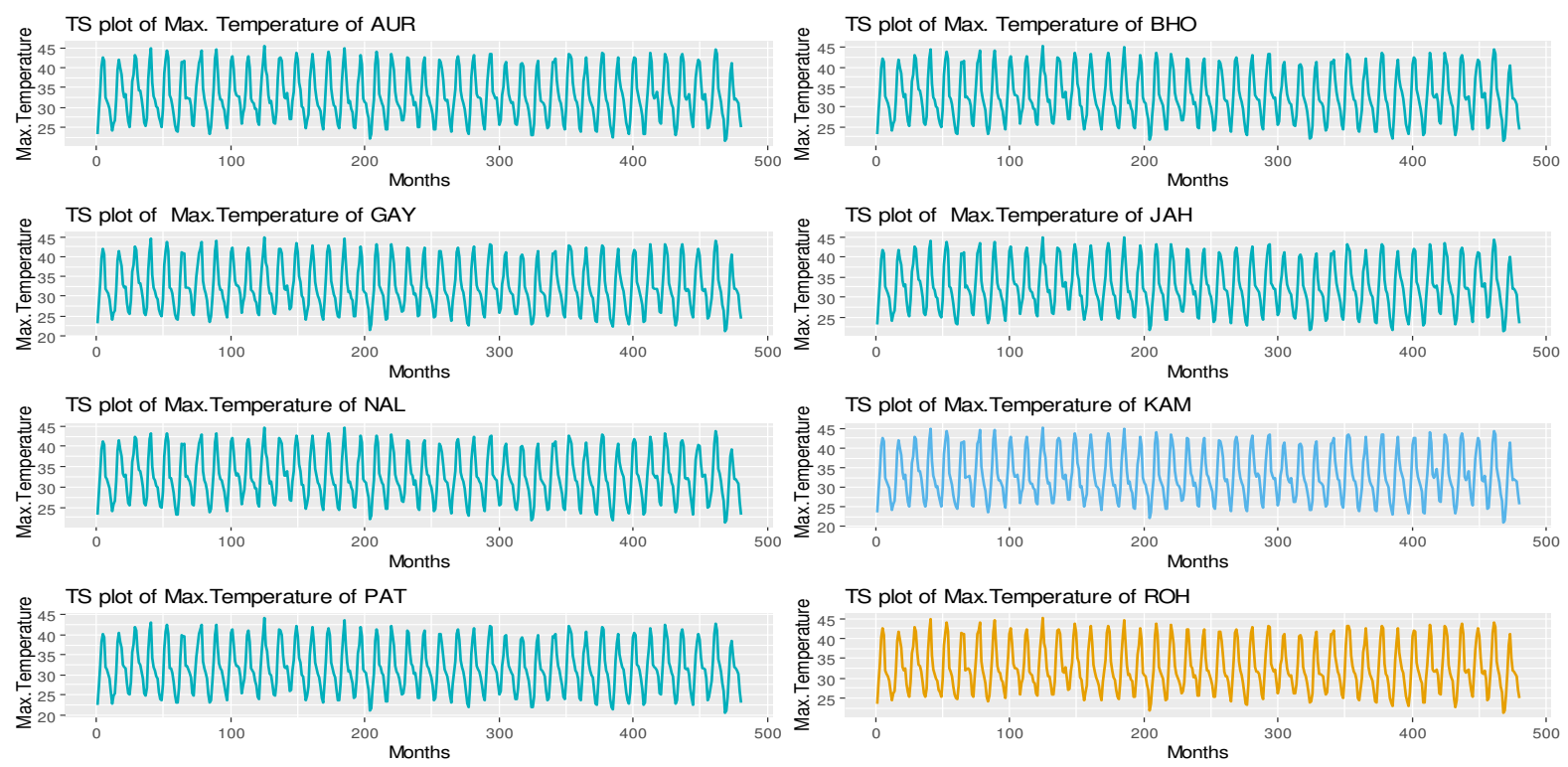

Fig. 2: Time series plots for monthly maximum temperature. 

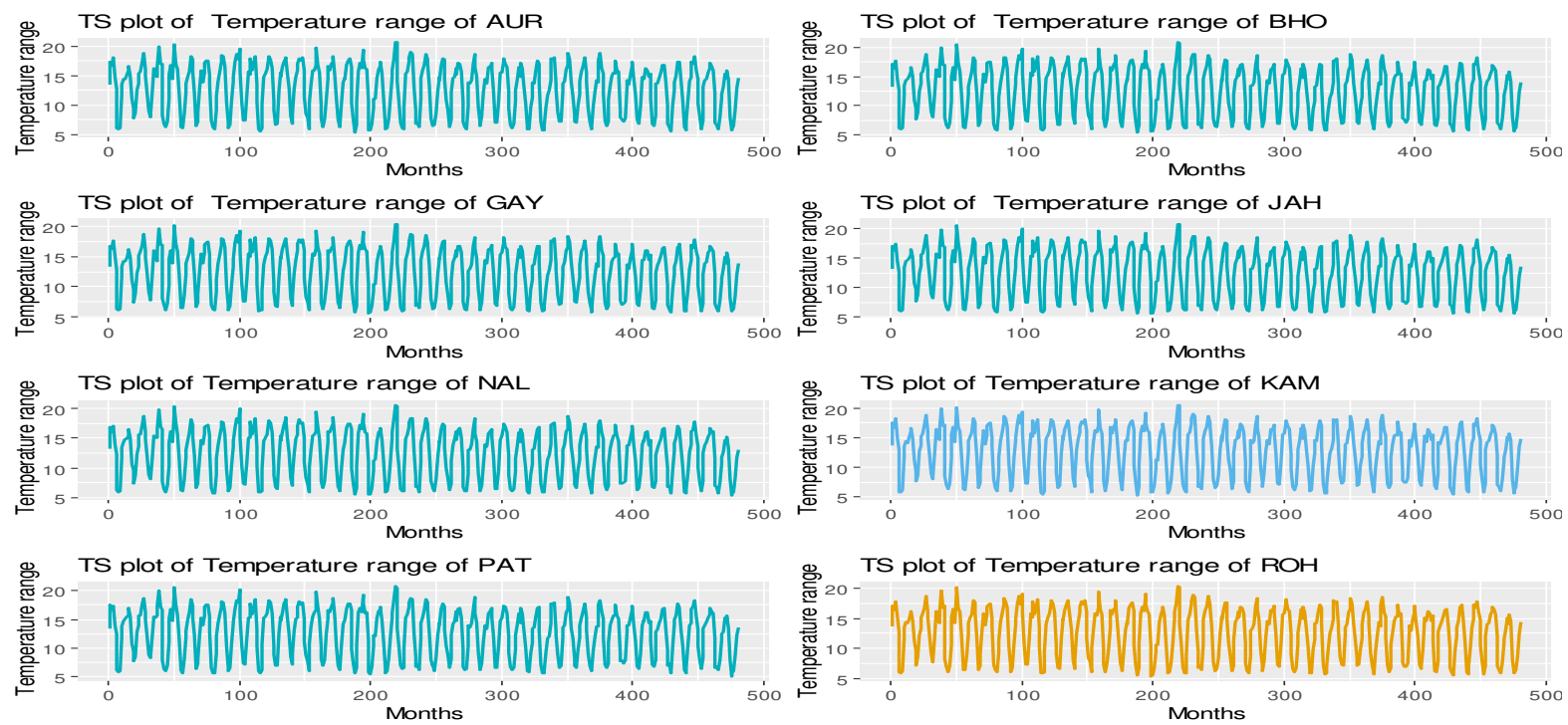

Fig. 3: Time series plots for monthly temperature range.

\subsection{Identification:}

The model identification is a very crucial step for spatio- temporal modelling. First the presence of correlation in space-time data is checked. The values of chi-square of Multivariate Box-Pierce test for maximum temperature and temperature range are 3346.149 and 2824.946 with $p$ value $<0.001$ respectively which tell that reject the null hypothesis $\left(H_{0}\right.$ : non-correlation) at $1 \%$ level of significance. After checking the presence of spacetime correlation, the suitable candidate STRAMA model has been selected with help of ST-ACF and ST-PACF plots. The ST-ACF and ST-PACF plots of original data series have shown the presence of seasonality. Therefore, seasonally adjusted data of ST-ACF and ST-PACF plots are used to determine STARMA model (Fig. 4 and 5). Here STAR $\left(1_{1}\right)$ and STMA $(0)$ have been selected for both the maximum temperature and temperature range. Therefore, the STARMA $\left(1_{1}, 0,0\right)$ model has been identified. This model is also called STAR $\left(1_{1}\right)$ model.
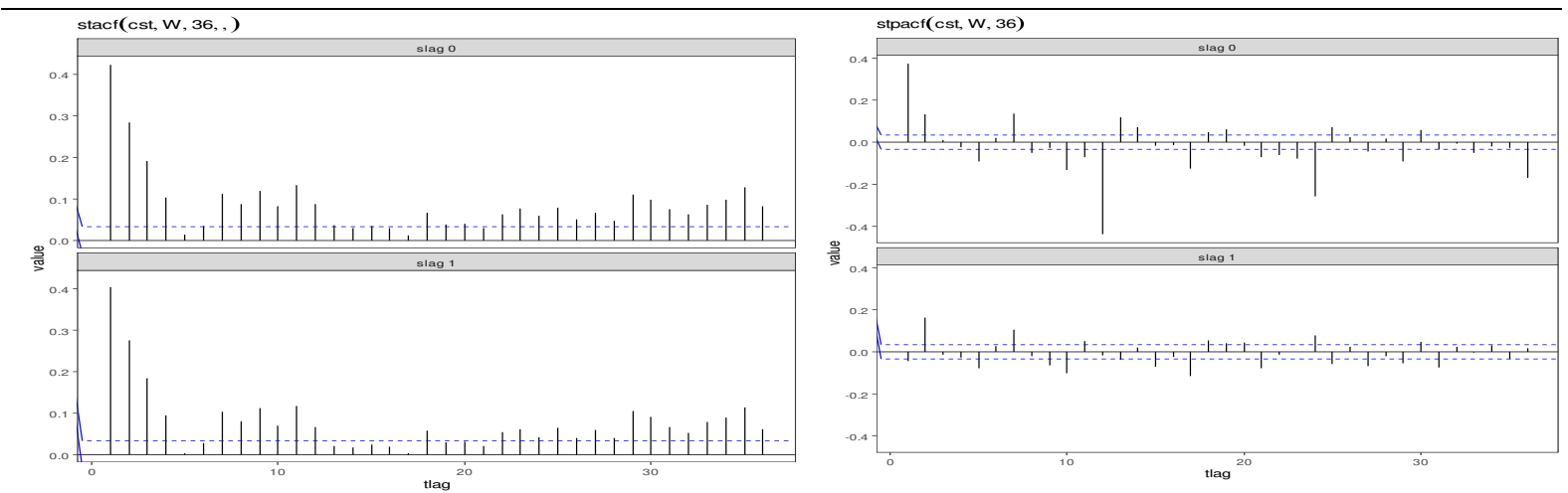

Fig. 4: ST-ACF and ST-PACF plots for seasonality adjusted data series of temperature range 


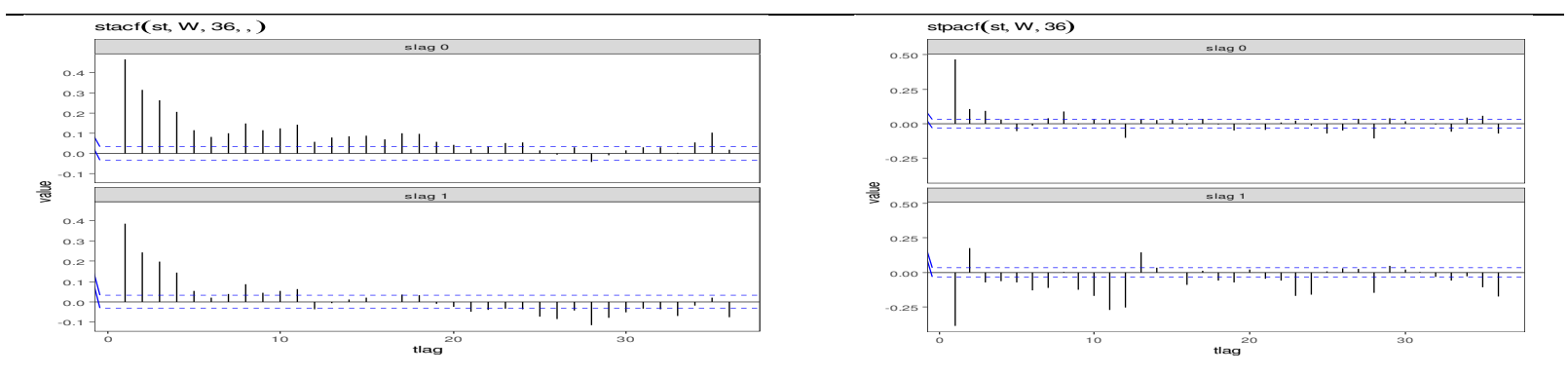

Fig. 5: ST-ACF and ST-PACF plots for seasonality adjusted data series of maximum temperature

\subsection{Estimation:}

Parameters of the fitted STARMA $\left(1_{1}, 0,0\right)$ model is estimated by maximum likelihood method. The estimated parameters and its standard error are presented in Table 6. All the estimated parameters are statistically significant at $5 \%$ level of significance. The STARMA $\left(1_{1}, 0,0\right)$ model can be expressed as:

$$
\begin{aligned}
& \boldsymbol{Z}_{t}=0.562821\left(\boldsymbol{W}^{0}\right) \boldsymbol{Z}_{t-1}-0.142759\left(\boldsymbol{W}^{1}\right) \boldsymbol{Z}_{t-1}+\boldsymbol{\varepsilon}_{t}, \\
& \boldsymbol{Z}_{t}=0.808697\left(\boldsymbol{W}^{0}\right) \boldsymbol{Z}_{t-1}-0.384389\left(\boldsymbol{W}^{1}\right) \boldsymbol{Z}_{t-1}+\boldsymbol{\varepsilon}_{t},
\end{aligned}
$$

where the equations (19) and (20) represent the STARMA models for temperature range and maximum temperature respectively.

Table 6: Parameters estimate for STARMA $\left(1_{1}, 0,0\right)$ model

\begin{tabular}{ccc}
\hline Parameters & Estimated (Temp. Range) & Estimated (Max. Temp.) \\
\hline$\phi_{10}$ & $0.5628 * *(0.0647)$ & $0.8086^{* *}(0.040)$ \\
$\phi_{11}$ & $-0.1427 *(0.0662)$ & $-0.3843 * *(0.042)$ \\
$\boldsymbol{\sigma}^{2}$ & 3.1850 & 4.5591 \\
$\log$ likelihood & -4938.03 & -4810.747 \\
BIC & 9892.517 & 9637.949
\end{tabular}

values in the parenthesis indicates the standard error, * \&** are the significant at $1 \% \& 5 \%$ level of significance respectively.

\subsection{Diagnostic checking:}

After parameters estimation, diagnostic checking of residuals is applied by using Multivariate Box-Pierce Non Correlation test. The test applied to the residuals give the chi-square statistics values as 390.25 and 455.12 with $p$ values $<0.001$ for maximum temperature and temperature range respectively, which tell that reject the null hypothesis $\left(H_{0}\right.$ : non-correlation) at $1 \%$ level of significance. Presence of spatio-temporal correlation within residuals also be seen in the ST-ACF and ST-PACF plots of residuals (Fig. 6 and 7). 


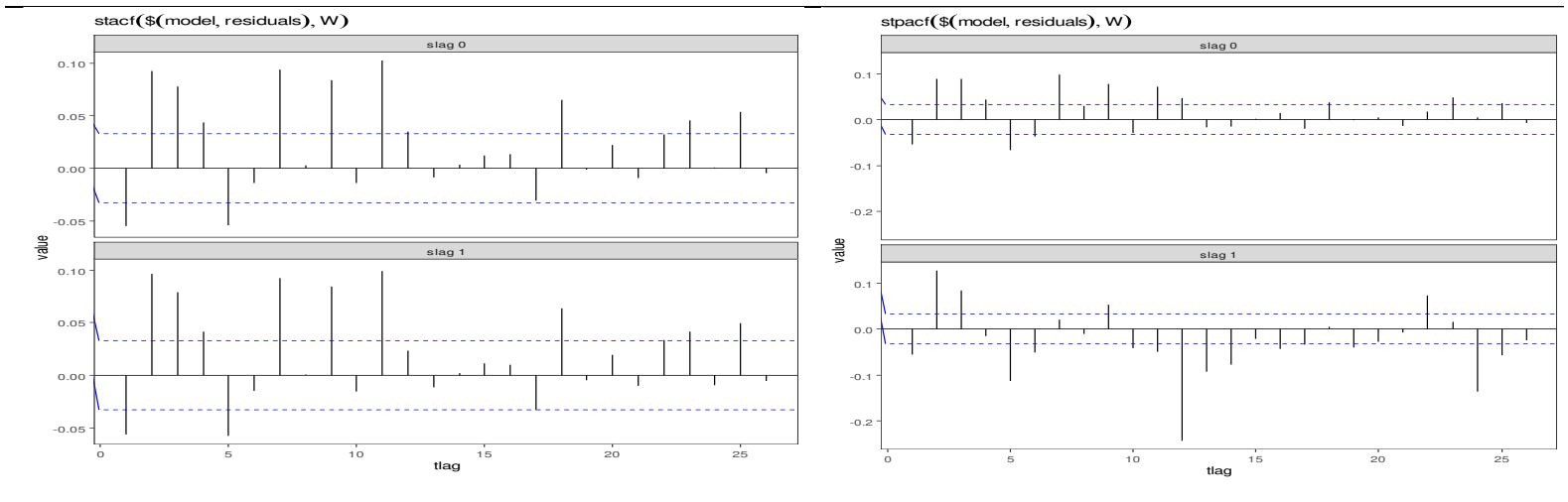

Fig. 6: ST-ACF and ST-PACF plots for residuals of temperature range
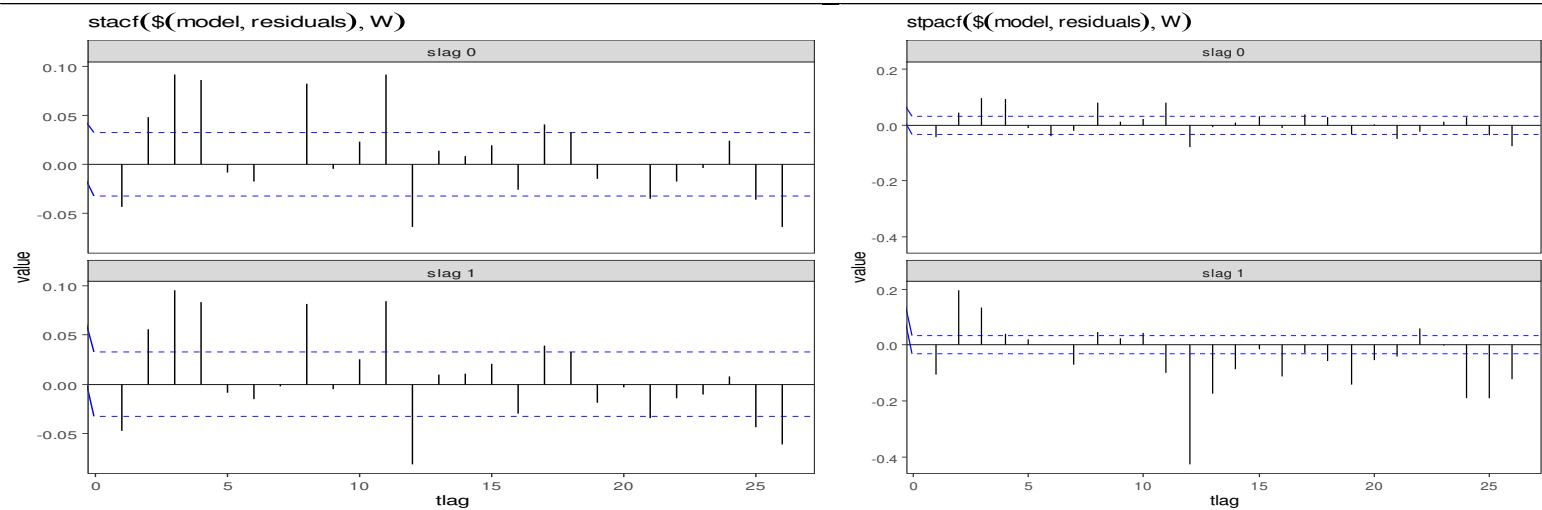

Fig. 7: ST-ACF and ST-PACF plots for residuals of maximum temperature

\subsection{BDS and ARCH-LM Test for Residuals:}

The BSD test results show the presence of both the linear and nonlinear patterns in the correlated residuals of maximum temperature and temperature range. The ARCH-LM test of square residuals are suffering from serial correlation in the most of the locations. Hence, it is necessary to develop a best fitted model for analysis of monthly temperature. A GARCH modelling is necessary to handle heteroscedasticity in the residuals series.

\subsection{Hybrid STARMA-GARCH Model:}

The STARMA-GARCH model is a combination of two models, first one is the STARMA model that take into account of mean behaviour of a space- time series and the second one is the GARCH model that used to model the variance of the series. In this hybrid model, residuals of the fitted STARMA model are used for suitable GARCH modelling. The results of minimum AIC and BIC values, the GARCH $(0,1)$ model is found to be the best fitted model for monthly maximum temperature and temperature range. The estimated model parameters are presented in Tables 7 and 8. For diagnostics of the hybrid model, Ljung-Box $Q$-test are applied to the residuals of the fitted hybrid STARMA $\left(1_{1}, 0,0\right)-\operatorname{GARCH}(0,1)$ model. The test results revealed that null hypothesis $\left(H_{0}\right.$ : no serial correlation) is accepted and indicate the residuals of hybrid model have no autocorrelation. Therefore, the fitted hybrid model is specified correctly and suitable for forecasting for temperature.

Table 7: Estimated parameters of GARCH $(0,1)$ model for max. temperature

\begin{tabular}{ccccccccc}
\hline District & AUR & BHO & GAY & JAH & NAL & KAM & PAT & ROH \\
\hline Parameter & Estimate & Estimate & Estimate & Estimate & Estimate & Estimate & Estimate & Estimate \\
\hline $\boldsymbol{\mu}$ & 0.0405 & 0.0130 & -0.0160 & -0.0249 & -0.0390 & 0.0584 & -0.0949 & 0.0392 \\
\hline
\end{tabular}




\begin{tabular}{ccccccccc}
\hline & $(0.0393)$ & $(0.0390)$ & $(0.0377)$ & $(0.0384)$ & $(0.0379)$ & $(0.0395)$ & $(0.0375)$ & $(0.0386)$ \\
& 0.0484 & 0.0459 & 0.0621 & 0.0392 & 0.0295 & 0.0489 & 0.0292 & 0.0569 \\
$\boldsymbol{A R} \boldsymbol{R}$ & $(0.0464)$ & $(0.0464)$ & $(0.0464)$ & $(0.0464$ & $(0.0463$ & $(0.0464)$ & $(0.0465$ & $(0.0464)$ \\
& 0.0049 & 0.0027 & 0.0023 & 0.0026 & 0.0029 & 0.0064 & 0.0010 & 0.0030 \\
$\boldsymbol{\omega}$ & $(0.0008)$ & $(0.0006)$ & $(0.0004)$ & $(0.0005)$ & $(0.0016)$ & $(0.0009)$ & $(0.0001)$ & $(0.0009)$ \\
& 0.9934 & 0.9961 & 0.9965 & 0.9962 & 0.9955 & 0.9916 & 0.9983 & 0.9958 \\
$\boldsymbol{\beta}$ & $(0.0011)$ & $(0.0009)$ & $(0.0006)$ & $(0.0008)$ & $(0.0025)$ & $(0.0012)$ & $(0.0001)$ & $(0.0013)$ \\
\hline
\end{tabular}

values in the parenthesis indicate standard error

Table 8: Estimated parameters of GARCH $(0,1)$ model for temperature range.

\begin{tabular}{ccccccccc}
\hline District & AUR & BHO & GAY & JAH & NAL & KAM & PAT & ROH \\
\hline Parameter & Estimate & Estimate & Estimate & Estimate & Estimate & Estimate & Estimate & Estimate \\
\hline \multirow{2}{*}{$\boldsymbol{\mu}$} & 0.0315 & 0.0100 & -0.0450 & -0.0308 & -0.0844 & 0.0685 & 0.00072 & -0.0006 \\
& $(0.0396)$ & $(0.0404)$ & $(0.0393)$ & $(0.0400)$ & $(0.0395)$ & $(0.039)$ & $(0.0401)$ & $(0.0391)$ \\
\multirow{3}{*}{$\boldsymbol{R} \boldsymbol{1}$} & -0.0655 & -0.0457 & -0.0588 & -0.0371 & -0.0361 & -0.0879 & -0.0394 & 0.0709 \\
& $(0.0463)$ & $(0.0463)$ & $(0.0463)$ & $(0.0463)$ & $(0.0463)$ & 0.0462 & $(0.0463)$ & $(0.0463)$ \\
\multirow{2}{*}{} & 0.0006 & 0.0015 & 0.0005 & 0.0034 & 0.0006 & 0.0059 & 0.0006 & 0.0005 \\
& $(0.000)$ & $(0.0001)$ & $(0.000)$ & $(0.001)$ & $(0.0000)$ & $(0.0009)$ & $(0.0000)$ & $(0.000)$ \\
$\boldsymbol{\beta}$ & 0.999 & 0.9977 & 0.999 & 0.9954 & 0.999 & 0.9925 & 0.999 & 0.999 \\
& $(0.000)$ & $(0.0002)$ & $(0.0000)$ & $(0.0020)$ & $(0.0000)$ & $(0.001)$ & $(0.0000)$ & $(0.0000)$ \\
\hline
\end{tabular}

values in the parenthesis indicate standard error

\subsection{Comparative Analysis}

To evaluate the forecast efficiency, MAPE has been computed for the forecasting performance for all eight locations. The MAPE values under training data set for maximum temperature and temperature range are given in Table 9. According to the results of the MAPE, the hybrid model has lowest mean absolute percentage errors compared to STARMA model for both the maximum temperature and temperature range in all eight locations. Further, forecasts have been carried out for model validation. The forecast values along with the forecast mean absolute percentage errors are given in Tables $\mathbf{1 0}$ to $\mathbf{1 7}$ for all eight locations. It can be seen from the table that the hybrid model is more reliable and that the error between the forecast values and validation data values (actual values) is smaller and forecast values are very close to validation data values for all eight locations. Hence, overall, it can be concluded that the fitted hybrid model performed better than the STARMA model for both the variables viz., maximum temperature and temperature range in all eight locations.

Table 9: Model performance under training for monthly temperature.

\begin{tabular}{ccccc}
\hline & \multicolumn{2}{c}{ Maximum temperature } & \multicolumn{2}{c}{ Temperature range } \\
\cline { 2 - 5 } Location & STARMA model & Hybrid model & STARMA model & Hybrid model \\
\hline AUR & 2.0647 & 0.1520 & 6.1119 & 0.4884 \\
BHO & 2.0566 & 0.1019 & 6.1438 & 0.3011 \\
GAY & 2.0415 & 0.1359 & 6.1289 & 0.5127 \\
\hline
\end{tabular}




\begin{tabular}{ccccc}
\hline JAH & 2.0286 & 0.1052 & 8.6080 & 0.3382 \\
NAL & 1.9940 & 0.1279 & 6.1425 & 0.7804 \\
KAM & 2.0730 & 0.1963 & 6.1351 & 0.7771 \\
PAT & 2.0415 & 0.3076 & 6.1419 & 0.2505 \\
ROH & 2.0751 & 0.1571 & 6.1347 & 0.4445 \\
\hline
\end{tabular}

Table 10: Model performance under testing data set for maximum temperature

\begin{tabular}{|c|c|c|c|c|c|c|}
\hline \multirow[b]{3}{*}{ Series } & \multirow[b]{3}{*}{ Actual } & \multicolumn{2}{|c|}{ Aurangabad } & \multirow[b]{3}{*}{ Actual } & \multicolumn{2}{|c|}{ Bhojpur } \\
\hline & & \multicolumn{2}{|c|}{ Forecast } & & \multicolumn{2}{|c|}{ Forecast } \\
\hline & & STARMA & Hybrid & & STARMA & Hybrid \\
\hline Jan-20 & 22.024 & 23.318 & 23.177 & 21.945 & 23.238 & 23.131 \\
\hline Feb-20 & 25.805 & 25.816 & 25.781 & 25.711 & 25.737 & 25.728 \\
\hline Mar-20 & 32.130 & 32.530 & 32.49 & 32.019 & 32.429 & 32.417 \\
\hline Apr-20 & 38.608 & 36.855 & 36.815 & 38.446 & 36.726 & 36.714 \\
\hline May-20 & 41.119 & 40.371 & 40.331 & 40.610 & 39.943 & 39.930 \\
\hline Jun-20 & 35.550 & 34.342 & 34.302 & 35.632 & 34.417 & 34.404 \\
\hline Jul-20 & 32.050 & 33.001 & 32.961 & 32.04 & 32.987 & 32.975 \\
\hline Aug-20 & 32.131 & 31.375 & 31.335 & 32.159 & 31.407 & 31.394 \\
\hline Sep-20 & 31.650 & 32.782 & 32.742 & 31.593 & 32.726 & 32.713 \\
\hline Oct-20 & 31.111 & 30.365 & 30.325 & 30.812 & 30.127 & 30.115 \\
\hline Nov-20 & 27.502 & 29.483 & 29.443 & 26.762 & 28.859 & 28.847 \\
\hline Dec-20 & 25.070 & 25.179 & 25.139 & 24.237 & 24.500 & 24.487 \\
\hline \multicolumn{2}{|c|}{ MAPE } & 2.988 & 2.929 & MAPE & 3.068 & 3.021 \\
\hline
\end{tabular}

Table 11: Model performance under testing data set for maximum temperature

\begin{tabular}{|c|c|c|c|c|c|c|}
\hline \multirow[b]{3}{*}{ Series } & \multirow[b]{3}{*}{ Actual } & \multicolumn{2}{|c|}{ Gaya } & \multirow[b]{3}{*}{ Actual } & \multirow{2}{*}{\multicolumn{2}{|c|}{$\begin{array}{c}\text { Jahanabad } \\
\text { Forecast }\end{array}$}} \\
\hline & & \multicolumn{2}{|c|}{ Forecast } & & & \\
\hline & & STARMA & Hybrid & & STARMA & Hybrid \\
\hline Jan-20 & 21.695 & 22.987 & 22.882 & 21.766 & 23.067 & 23.014 \\
\hline Feb-20 & 25.506 & 25.546 & 25.570 & 25.497 & 25.551 & 25.580 \\
\hline Mar-20 & 31.138 & 31.691 & 31.707 & 31.786 & 32.228 & 32.253 \\
\hline Apr-20 & 37.884 & 36.261 & 36.277 & 38.114 & 36.452 & 36.478 \\
\hline May-20 & 40.495 & 39.850 & 39.867 & 39.977 & 39.415 & 39.440 \\
\hline Jun-20 & 35.103 & 33.981 & 33.998 & 35.645 & 34.432 & 34.458 \\
\hline Jul-20 & 31.952 & 32.913 & 32.930 & 31.984 & 32.935 & 32.961 \\
\hline Aug-20 & 31.743 & 31.064 & 31.080 & 32.104 & 31.367 & 31.392 \\
\hline Sep-20 & 31.181 & 32.384 & 32.401 & 31.516 & 32.657 & 32.683 \\
\hline
\end{tabular}




\begin{tabular}{ccccccc}
\hline Oct-20 & 30.375 & 29.765 & 29.781 & 30.688 & 30.030 & 30.056 \\
Nov-20 & 26.516 & 28.65 & 28.672 & 26.353 & 28.514 & 28.540 \\
Dec-20 & 24.185 & 24.457 & 24.473 & 23.473 & 23.873 & 23.898 \\
\hline \multicolumn{2}{c}{ MAPE } & $\mathbf{3 . 0 9 8 2}$ & $\mathbf{3 . 0 6 9 3 6 7}$ & MAPE & $\mathbf{3 . 1 4 1 1}$ & $\mathbf{3 . 1 3 6}$ \\
\hline
\end{tabular}

Table 12: Model performance under testing data set for maximum temperature

\begin{tabular}{|c|c|c|c|c|c|c|}
\hline \multirow[b]{3}{*}{ Series } & \multirow[b]{3}{*}{ Actual } & \multicolumn{2}{|c|}{ Nalanda } & \multirow[b]{3}{*}{ Actual } & \multicolumn{2}{|c|}{ Kaimur } \\
\hline & & \multicolumn{2}{|c|}{ Forecast } & & \multicolumn{2}{|c|}{ Forecast } \\
\hline & & STARMA & Hybrid & & STARMA & Hybrid \\
\hline Jan-20 & 21.693 & 23.001 & 22.982 & 21.634 & 22.943 & 22.782 \\
\hline Feb-20 & 25.361 & 25.440 & 25.482 & 25.585 & 25.606 & 25.553 \\
\hline Mar-20 & 31.677 & 32.134 & 32.174 & 32.021 & 32.424 & 32.366 \\
\hline Apr-20 & 37.654 & 36.075 & 36.114 & 38.534 & 36.793 & 36.735 \\
\hline May-20 & 39.270 & 38.825 & 38.864 & 41.341 & 40.554 & 40.496 \\
\hline Jun-20 & 35.549 & 34.357 & 34.396 & 35.279 & 34.121 & 34.063 \\
\hline Jul-20 & 31.872 & 32.838 & 32.877 & 31.93 & 32.900 & 32.842 \\
\hline Aug-20 & 31.970 & 31.261 & 31.300 & 32.065 & 31.324 & 31.266 \\
\hline Sep-20 & 31.398 & 32.555 & 32.594 & 31.674 & 32.800 & 32.742 \\
\hline Oct-20 & 30.684 & 30.033 & 30.072 & 31.501 & 30.693 & 30.635 \\
\hline Nov-20 & 26.284 & 28.450 & 28.490 & 28.364 & 30.195 & 30.137 \\
\hline Dec-20 & 23.084 & 23.557 & 23.597 & 25.532 & 25.567 & 25.509 \\
\hline & & 3.151 & 3.167 & MAPE & 2.930 & 2.874 \\
\hline
\end{tabular}

Table 13: Model performance under testing data set for maximum temperature

\begin{tabular}{|c|c|c|c|c|c|c|}
\hline \multirow[b]{3}{*}{ Series } & \multirow[b]{3}{*}{ Actual } & \multicolumn{2}{|c|}{ Patna } & \multirow[b]{3}{*}{ Actual } & \multirow{2}{*}{\multicolumn{2}{|c|}{$\begin{array}{c}\text { Rohtas } \\
\text { Forecast }\end{array}$}} \\
\hline & & \multicolumn{2}{|c|}{ Forecast } & & & \\
\hline & & STARMA & Hybrid & & STARMA & Hybrid \\
\hline Jan-20 & 21.050 & 22.412 & 22.447 & 21.929 & 23.205 & 23.057 \\
\hline Feb-20 & 24.564 & 24.714 & 24.810 & 25.777 & 25.797 & 25.764 \\
\hline Mar-20 & 30.403 & 31.085 & 31.179 & 31.385 & 31.898 & 31.858 \\
\hline Apr-20 & 36.741 & 35.287 & 35.382 & 38.156 & 36.498 & 36.459 \\
\hline May-20 & 38.627 & 38.322 & 38.417 & 41.061 & 40.310 & 40.271 \\
\hline Jun-20 & 34.739 & 33.657 & 33.752 & 35.050 & 33.946 & 33.907 \\
\hline Jul-20 & 31.840 & 32.848 & 32.943 & 31.862 & 32.827 & 32.788 \\
\hline Aug-20 & 31.611 & 30.928 & 31.023 & 31.662 & 31.007 & 30.968 \\
\hline Sep-20 & 30.941 & 32.216 & 32.311 & 31.185 & 32.374 & 32.335 \\
\hline Oct-20 & 30.163 & 29.558 & 29.653 & 30.504 & 29.886 & 29.847 \\
\hline Nov-20 & 25.897 & 28.176 & 28.271 & 27.013 & 29.052 & 29.013 \\
\hline Dec-20 & 22.906 & 23.359 & 23.454 & 24.880 & 25.050 & 25.011 \\
\hline \multicolumn{2}{|c|}{ MAPE } & 3.285 & 3.356 & MAPE & 3.002 & 2.934 \\
\hline
\end{tabular}


Table 14: Model performance under testing data set for temperature range

\begin{tabular}{|c|c|c|c|c|c|c|}
\hline \multirow[b]{3}{*}{ Series } & \multirow[b]{3}{*}{ Actual } & \multicolumn{2}{|c|}{ Aurangabad } & \multirow[b]{3}{*}{ Actual } & \multicolumn{2}{|c|}{ Bhojpur } \\
\hline & & \multicolumn{2}{|c|}{ Forecast } & & \multicolumn{2}{|c|}{ Forecast } \\
\hline & & STARMA & Hybrid & & $\begin{array}{l}\text { STARMA } \\
\text { TARM }\end{array}$ & Hybrid \\
\hline Jan-20 & 13.160 & 13.003 & 13.136 & 13.020 & 12.874 & 12.952 \\
\hline Feb-20 & 15.326 & 14.619 & 14.644 & 15.226 & 14.540 & 14.547 \\
\hline Mar-20 & 14.650 & 14.167 & 14.199 & 14.560 & 14.089 & 14.099 \\
\hline Apr-20 & 15.882 & 15.066 & 15.098 & 15.836 & 15.033 & 15.043 \\
\hline May-20 & 14.490 & 14.048 & 14.079 & 14.217 & 13.835 & 13.845 \\
\hline Jun-20 & 7.903 & 9.018 & 9.050 & 7.949 & 9.055 & 9.065 \\
\hline Jul-20 & 5.672 & 7.351 & 7.383 & 5.613 & 7.303 & 7.313 \\
\hline Aug-20 & 5.954 & 7.543 & 7.575 & 5.942 & 7.536 & 7.546 \\
\hline Sep-20 & 6.415 & 7.913 & 7.944 & 6.226 & 7.767 & 7.777 \\
\hline Oct-20 & 9.207 & 10.016 & 10.048 & 8.765 & 9.682 & 9.692 \\
\hline Nov-20 & 12.890 & 12.826 & 12.857 & 12.312 & 12.386 & 12.396 \\
\hline Dec-20 & 14.572 & 14.091 & 14.122 & 14.060 & 13.703 & 13.713 \\
\hline \multicolumn{2}{|c|}{ MAPE } & 10.303 & 10.308 & MAPE & 10.486 & 10.478 \\
\hline
\end{tabular}

Table 15: Model performance under testing data set for temperature range

\begin{tabular}{|c|c|c|c|c|c|c|}
\hline \multirow[b]{3}{*}{ Series } & \multirow[b]{3}{*}{ Actual } & \multicolumn{2}{|c|}{ Gaya } & \multirow[b]{3}{*}{ Actual } & \multicolumn{2}{|c|}{ Jahanabad } \\
\hline & & \multicolumn{2}{|c|}{ Forecast } & & \multicolumn{2}{|c|}{ Forecast } \\
\hline & & STARMA & Hybrid & & STARMA & Hybrid \\
\hline Jan-20 & 12.915 & 12.771 & 12.830 & 12.789 & 12.670 & 12.691 \\
\hline Feb-20 & 15.044 & 14.341 & 14.290 & 14.982 & 14.351 & 14.318 \\
\hline Mar-20 & 13.884 & 13.580 & 13.536 & 14.349 & 13.916 & 13.885 \\
\hline Apr-20 & 15.660 & 14.868 & 14.823 & 15.618 & 14.869 & 14.838 \\
\hline Мay-20 & 14.343 & 13.942 & 13.897 & 13.834 & 13.538 & 13.507 \\
\hline Jun-20 & 8.098 & 9.150 & 9.105 & 8.032 & 9.121 & 9.090 \\
\hline Jul-20 & 5.982 & 7.594 & 7.549 & 5.531 & 7.237 & 7.206 \\
\hline Aug-20 & 6.044 & 7.602 & 7.557 & 5.895 & 7.503 & 7.473 \\
\hline Sep-20 & 6.263 & 7.804 & 7.759 & 6.057 & 7.636 & 7.605 \\
\hline Oct-20 & 8.450 & 9.435 & 9.390 & 8.465 & 9.456 & 9.426 \\
\hline Nov-20 & 11.971 & 12.133 & 12.088 & 11.926 & 12.091 & 12.060 \\
\hline Dec-20 & 13.902 & 13.578 & 13.533 & 13.486 & 13.269 & 13.238 \\
\hline \multicolumn{2}{|c|}{ МАPE } & 10.125 & 9.911 & MAPE & 10.631 & 10.491 \\
\hline
\end{tabular}


Table 16: Model performance under testing data set for temperature range

\begin{tabular}{|c|c|c|c|c|c|c|}
\hline \multirow[b]{3}{*}{ Series } & \multirow[b]{3}{*}{ Actual } & \multicolumn{2}{|c|}{ Nalanda } & \multirow[b]{3}{*}{ Actual } & \multicolumn{2}{|c|}{ Kaimur } \\
\hline & & \multicolumn{2}{|c|}{ Forecast } & & \multicolumn{2}{|c|}{ Forecast } \\
\hline & & STARMA & Hybrid & & STARMA & Hybrid \\
\hline Jan-20 & 12.592 & 12.497 & 12.458 & 13.029 & 12.877 & 13.091 \\
\hline Feb-20 & 14.742 & 14.174 & 14.087 & 15.201 & 14.503 & 14.559 \\
\hline Mar-20 & 14.223 & 13.807 & 13.723 & 14.616 & 14.134 & 14.203 \\
\hline Apr-20 & 15.305 & 14.637 & 14.553 & 15.780 & 14.980 & 15.049 \\
\hline May-20 & 13.420 & 13.216 & 13.131 & 14.595 & 14.126 & 14.195 \\
\hline Jun-20 & 8.089 & 9.170 & 9.085 & 7.845 & 8.971 & 9.039 \\
\hline Jul-20 & 5.424 & 7.151 & 7.066 & 5.679 & 7.357 & 7.426 \\
\hline Aug-20 & 5.792 & 7.429 & 7.345 & 6.022 & 7.593 & 7.662 \\
\hline Sep-20 & 5.885 & 7.502 & 7.417 & 6.650 & 8.092 & 8.160 \\
\hline Oct-20 & 8.260 & 9.304 & 9.219 & 9.763 & 10.437 & 10.506 \\
\hline Nov-20 & 11.714 & 11.927 & 11.843 & 13.542 & 13.321 & 13.390 \\
\hline Dec-20 & 13.050 & 12.940 & 12.856 & 14.841 & 14.294 & 14.363 \\
\hline \multicolumn{2}{|c|}{ MAPE } & 10.804 & 10.103 & MAPE & 10.477 & 10.231 \\
\hline
\end{tabular}

Table 17: Model performance under testing data set for temperature range

\begin{tabular}{|c|c|c|c|c|c|c|}
\hline \multirow[b]{3}{*}{ Series } & \multirow[b]{3}{*}{ Actual } & \multicolumn{2}{|c|}{ Patna } & \multirow[b]{3}{*}{ Actual } & \multicolumn{2}{|c|}{ Rohtas } \\
\hline & & \multicolumn{2}{|c|}{ Forecast } & & \multicolumn{2}{|c|}{ Forecast } \\
\hline & & STARMA & Hybrid & & STARMA & Hybrid \\
\hline Jan-20 & 12.861 & 12.803 & 12.849 & 13.166 & 12.984 & 13.105 \\
\hline Feb-20 & 15.198 & 14.591 & 14.589 & 15.201 & 14.481 & 14.472 \\
\hline Mar-20 & 14.862 & 14.325 & 14.325 & 14.000 & 13.674 & 13.674 \\
\hline Apr-20 & 15.591 & 14.880 & 14.880 & 15.698 & 14.906 & 14.905 \\
\hline May-20 & 13.541 & 13.316 & 13.316 & 14.615 & 14.149 & 14.148 \\
\hline Jun-20 & 7.808 & 8.966 & 8.967 & 8.016 & 9.092 & 9.092 \\
\hline Jul-20 & 5.074 & 6.886 & 6.887 & 5.924 & 7.549 & 7.548 \\
\hline Aug-20 & 5.617 & 7.301 & 7.301 & 5.935 & 7.522 & 7.521 \\
\hline Sep-20 & 5.933 & 7.537 & 7.538 & 6.344 & 7.864 & 7.863 \\
\hline Oct-20 & 8.684 & 9.628 & 9.629 & 8.669 & 9.602 & 9.602 \\
\hline Nov-20 & 12.255 & 12.337 & 12.337 & 12.389 & 12.450 & 12.449 \\
\hline Dec-20 & 13.651 & 13.398 & 13.399 & 14.316 & 13.893 & 13.892 \\
\hline \multicolumn{2}{|c|}{ МАРE } & 11.270 & 11.245 & MAPE & 10.204 & 10.129 \\
\hline
\end{tabular}




\section{Conclusions}

In this study, the problem is to forecast the monthly maximum temperature and temperature range as a spatio-temporal forecasting problem for III-B agro climatic zone of Bihar. In the real-world phenomena, weather parameters work in a very complex manner such they can vary over small regions and for short periods of time which lead to linear, as well as nonlinear patterns. In these variations there are various statistical techniques used in forecasting of weather parameters. One of the most popular statistical method used for forecasting temperature time series is Box-Jenkins ARIMA but this model is suitable for only univariate and linear time series data. If the multivariate spatio-temporal time series data set shows non-linear pattern, then ARIMA model is not suitable for its modelling. In order to overcome the drawback of traditionally used models, hybrid model combining the STARMA and GARCH have been investigated. Based on the results obtained by the STARMA model and hybrid model for both the variables viz., maximum temperature and temperature range, it can be seen that fitted hybrid model performed better as compared to STARMA model for the training data set. After validation of proposed hybrid model, the fitted hybrid model has lower forecast errors than the STARMA model. Hence, it can be concluded that the spatio-temporal hybrid model has better forecasting accuracy because of the inclusion of both spatial information and nonlinear patterns in the temperature data sets. The proposed hybrid model also be used to model variations is other weather parameters, which will be taken up in a forth coming paper.

Acknowledgements: We are grateful to the department of Agricultural Statistics, Visva-Bharati University for all sort of assistance provided during this study.

Funding: The authors declare that no funds, grants, or other support were received during the preparation of this manuscript.

Author Contributions: All authors contributed to the study conception and design. Material preparation, data collection and analysis were performed by Ravi Ranjan Kumar and Kader Ali Sarkar. The first draft of the manuscript was written by Ravi Ranjan Kumar. Kader Ali Sarkar, Debasis Bhattacharya, and Digvijay Singh Dhakre commented on its for its improvement. All authors read and approved the final manuscript.

Data availability: Data have been recorded form the NASA prediction of worldwide energy resources (https://power.larc.nasa.gov), which are freely available.

Code availability: The codes written for the current study are available on reasonable request from the corresponding author.

\section{Declarations}

Conflict Interests: The authors declare that they have no conflict of interest.

Ethical approval: The authors confirm that this work is original and has not been published elsewhere nor is it currently under consideration for publication elsewhere.

Consent to participate: All authors contents to participate.

Consent to publication: All authors contents to publication. 


\section{References}

Bollerslev T (1986) Generalized Autoregressive Conditional Heteroscedasticity. Journal Econometrics, 31(3):307-27.

Box GEP, Jenkins GM (1976) Time Series Analysis: Forecasting and Control. Holden-Day, Boca Raton, Fla., USA.

Brock WA, Dechert W and Scheinkman J (1996) A Test for Independence Based on the Correlation Dimension. Econometric Reviews. 15:197-235.

Brynjarsdottir J and Berliner LM (2014) Dimension-Reduced Modelling of Spatio-Temporal Processes. Journal of the American Statistical Association, 508(108):1647-59, $\underline{\text { https://doi.org/ }}$ $\underline{10.1080 / 01621459.2014 .904232}$

Dritsaki C (2018) The Performance of Hybrid ARIMA-GARCH Modeling and Forecasting Oil Price. International Journal of Energy Economics and Policy, 8(3):14-21.

Cliff AD and Ord, John K (1975a) Space-time modelling with an application to regional forecasting. Transactions of Institute of British Geographers, 64:119-28.

Cliff AD, Haggett P, Ord, JK, Bassett, K and Davies RB (1975) Elements of spatial structure: a quantitative approach (Cambridge).

Engle RF (1982) Autoregressive Conditional Heteroscedasticity with Estimates of Variance of United Kingdom Inflation. Econometrica, 50:987-1008.

Griffith DA (1996) Some Guidelines for Specifying the Geographic Weights Matrix Contained in Spatial Statistical Models. Practical Handbook of Spatial Statistics, 82-148, edited by S. L. Arlinghaus, D. A. Griffith, W. D. Drake and J. D. Nystuen. Boca Raton, FL: CRC Press.

Griffith DA and Heuvelink GBM (2009) Deriving Space-time Variograms from Space- time Autoregressive (STAR) Model Specifications. Paper presented at the StatGIS 2009 conference, Milos, Greece, June 17.

Gupta A and Robinson PM (2015) Inference on higher-order spatial autoregressive models with increasingly many parameters. Journal Economet, 186:19-31.

Kamarianakis Y and Prastacos P (2005) Space-time modelling of traffic flow. Computers \& Geosciences, 31:11933.

Ljung GM, Box GEP (1978) On a Measure of a Lack of Fit in Time Series Models. Biometrika. 65(2):297-303.

Pahlavani M and Roshan R (2015) The Comparison among ARIMA and hybrid ARIMA-GARCH Models in Forecasting the Exchange Rate of Iran. International Journal of Business and Development Studies, 7(1):31-50.

Pfeifer PE and Deutsch SJ (1980) A Comparison of Estimation Procedures for the Parameters of the STAR Model. Communication in Statistics, simulation and Computation, B9(3):255-70. 
Pfeifer PE and Deutsch SJ (1980c) Independence and Sphericity Tests for the residuals of Space Time ARIMA Models. Communication in Statistics, simulation and Computation, B9(5): 533-49.

Pfeifer PE and Deutsch SJ (1981) Variance of the Sample-Time Autocorrelation Function of Contemporaneously Correlated Variables. SIAM Journal of Applied Mathematics, Series A, 40(1):133-36.

Pfeifer PE and Deutsch SJ (1981a) Seasonal Space-Time ARIMA modelling. Geographical Analysis, 13(2):11733.

Pfeifer PE and Deutsch SJ (1981b) Space-Time ARMA Modelling with contemporaneously correlated innovations. Technometrics, 23(4): 410-09.

Rathod S, Gurung B, Singh KN, Ray M (2018) An improved space-time autoregressive moving average (STARMA) model for modelling and forecasting of spatio-temporal time-series data. Journal of the Indian Society of Agricultural Statistics, 72(3):239-53.

Saha A, Singh KN, Ray M, and Rathod S (2020) A hybrid spatio-temporal modelling: an application to spacetime rainfall forecasting. Theoretical and Applied Climatology. https://doi.org/10.1007/s00704-02003374-2

Kurta S and Tunay KB (2015) STARMA Models Estimation with Kalman Filter: The Case of Regional Bank Deposits. Procedia-Social and Behavioral Sciences, 195:2537-47. http//doi.org/ $\underline{10.1016 / j . s b s p r o .2015 .06 .441}$

Tong H, Lim KS (1980) Threshold autoregressive, limit cycles and cyclical data. Journal of the Royal Statistical Society, 42:245-92.

Yusof F, Kanea IL, and Yusopc Z (2013) Hybrid of ARIMA-GARCH Modeling in Rainfall Time Series. Journal Teknologi (Sciences \& Engineering), 63(2):27-34.

Zou J, Zhu J, Xie P and Xuan P (2018) A STARMA Model for Wind Power Space-Time Series. IEEE Power \& Energy Society General Meeting (PESGM).1-5. http//doi.org/10.1109/PESGM.2018.8585919 